\title{
KONDISI IKLIM DAN POTENSI TEGAKAN SENGON (Falcataria moluccana (Miq.)) DI HUTAN RAKYAT DESA JATI BALI KABUPATEN KONAWE SELATAN
}

Climate Conditions and Standing Potentials of Sengon (Falcataria moluccana (Miq.)) In The Community Forest on Jati Bali Village South Konawe Regency

\section{Aminuddin Mane Kandari, Safril Kasim, La Ode Agus Salim Mando, La Ode Midi dan Suhartin Triyani Palebangan}

\author{
Fakultas Kehutanan dan IImu Lingkungan, Universitas Halu Oleo \\ Kampus Abdullah Silondae, Jl. Mayjen. S.Parman, Kendari Sulawesi Tenggara \\ *Email : manekandaria@yahoo.com
}

Direvisi: 16/06/2020, Diterbitkan: 01/08/2020

\begin{abstract}
This study aims to determine the climatic conditions that occur at Sengon cultivation sites and determine the standing potential number of trees, base area, and volume of sengon stands in community plantation forests that follow the people's seed garden program. Data collection is carried out in August to November 2018. The location of this village is at the coordinates of $04^{\circ}$ $5^{\prime} 12^{\prime \prime}-04^{\circ} 3^{\prime} 15^{\prime \prime}$ LS and $122^{\circ} 24^{\prime} 00^{\prime \prime}-122^{\circ} 23^{\prime} 00^{\prime \prime}$ BT and at altitude of $108 \mathrm{~m}$ above sea level. The population in this study is the sengon stand with an area of 5.8 ha. The sample area is determined with an intensity of $6.2 \%$ and the area of 1 plot is 0.04 ha, so the number of plots is 9 units. The results showed that 1) climatic conditions in the study location are classified as type $B$ climate or wet (Schmidth-Ferguson method) including the category of tropical rain forests with an average number of wet months (BB) 9.2 and dry months (BK) 1.5 with a $Q$ value of 0.16 . Average annual rainfall is $2662.6 \mathrm{~mm}$, the monthly average rainfall of the highest in May was $347.4 \mathrm{~mm}$ with an average number of rainy days by 22.5 days and the lowest in September was $83.0 \mathrm{~mm}$ with an average rainy day of 11 days, while the longest rainy day occurred in April during 22.6 days with rainfall reaching $262.1 \mathrm{~mm}$ and the fastest occurred in October for 10.3 days with rainfall reaching $101.7 \mathrm{~mm}$. The average annual temperature is around $23^{\circ} \mathrm{C}$ with an $32^{\circ} \mathrm{C}$, with the lowest monthly average of $25.3^{\circ} \mathrm{C}$ (August) $-28.1^{\circ} \mathrm{C}$ (December). This fact indicates that the climatic conditions in Jati Bali Village South Konawe District are suitable for the development of sengon plants. 2) the potential of sengon stands in the village of Jati Bali South Konawe Regency, namely the number of trees 866 btgha $^{-1}$, base area of $9.76 \mathrm{~m}^{2} \mathrm{ha}^{-1}$, volume of stands of 94.15 $m^{3} h a^{-1}$.
\end{abstract}

Keywords; Community Forest; Climate Conditions; Standing Potential; Sengon

\begin{abstract}
ABSTRAK
Penelitian ini bertujuan untuk mengetahui kondisi iklim yang terjadi pada lokasi budidaya Sengon dan mengetahui potensi tegakannya, yang meliputi jumlah pohon, luas bidang dasar, dan volume tegakan sengon pada hutan rakyat yang mengikuti program Kebun Bibit Rakyat. Pengambilan data dilaksanakan pada bulan Agustus hingga November 2018. Lokasi desa ini berada pada titik koordinat $04^{\circ} 5^{\prime} 12^{\prime \prime}-04^{\circ} 3^{\prime} 15^{\prime \prime}$ LS dan $122^{\circ} 24^{\prime} 00^{\prime \prime}-122^{\circ} 23^{\prime} 00^{\prime \prime}$ BT dan pada ketinggian tempat $108 \mathrm{~m}$ dpl. Populasi pada penelitian ini yaitu tegakan sengon dengan luas 5.8 ha. Adapun luas sampel ditentukan dengan intensitas 6,2\% dan luas 1 petak ukur adalah 0.04 ha, sehingga jumlah petak ukur berjumlah 9 buah. Hasil penelitian menunjukkan bahwa 1) kondisi iklim lokasi penelitian tergolong tipe iklim B atau Basah (metode Schmidth-Fergusson), termasuk kategori hutan hujan tropika dengan jumlah rata-rata bulan basah (BB) 9.2 dan bulan kering (BK)
\end{abstract}


1.5 dengan nilai $Q$ sebesar 0.16. Curah hujan rata-rata tahunan adalah $2662.6 \mathrm{~mm}$, curah hujan rata-rata bulanan tertinggi pada bulan Mei sebesar $347.4 \mathrm{~mm}$ dengan jumlah hari hujan rata-rata sebesar 22.5 hari dan terendah pada bulan September sebesar $83.0 \mathrm{~mm}$ dengan hari hujan ratarata sebesar 11 hari, sementara hari hujan paling lama terjadi di bulan April selama 22.6 hari dengan curah hujan mencapai $262.1 \mathrm{~mm}$ dan tercepat terjadi di bulan Oktober selama 10.3 hari dengan curah hujan mencapai $101.7 \mathrm{~mm}$. Rata-rata suhu udara tahunan berkisar $23^{\circ} \mathrm{C}-32^{\circ} \mathrm{C}$, dengan rata - rata bulanan terendah $25.3^{\circ} \mathrm{C}$ (Agustus) $-28.1^{\circ} \mathrm{C}$ (Desember). Kenyataan tersebut mengindikasikan bahwa kondisi iklim di Desa Jati Bali Kabupaten Konawe Selatan sesuai untuk pengembangan tanaman sengon. 2) potensi tegakan sengon di desa Jati Bali Kabupaten Konawe Selatan, yakni jumlah pohon 866 btgha $^{-1}$, luas bidang dasar sebesar $9.76 \mathrm{~m}^{2} \mathrm{ha}^{-1}$, volume tegakan sebesar $94.15 \mathrm{~m}^{3} \mathrm{ha}^{-1}$.

Kata kunci: Hutan Rakyat; Kondisi Iklim; Potensi Tegakan; Sengon

\section{PENDAHULUAN}

Hutan mempunyai peranan penting dalam menjaga kestabilan ekosistem global. Keberadaan hutan tidak bisa lepas dari keadaan iklim dan kondisi tanah. Kandari et al. (2013; 2014; 2019a; 2020) menyatakan bahwa iklim merupakan salah satu faktor yang mempengaruhi produktivitas lahan dan tanaman, bahkan tipe vegetasi yang tumbuh di suatu daerah secara substansial menggambarkan kondisi iklim di tempat dimaksud. Kenyataan menunjukkan bahwa pada kondisi tertentu pengaruh iklim terhadap vegetasi yang tumbuh di suatu tempat jauh lebih kuat dibandingkan dengan pengaruh tanah. Menurut Bansook et al. (2011), pada tanah yang sama menunjukkan jenis vegetasi yang jauh berbeda akibat kondisi iklim yang berbeda.

Hubungan trilogi antara vegetasi, iklim, dan tanah yang terdesain secara alamiah dapat saja terganggu sebagai akibat pengelolaan hutan yang tidak tepat (Kandari et al., 2015; 2019b). Menurut Mando et al. (2018), silih berganti sistem pengelolaan hutan yang ada di dunia dan khususnya di Indonesia menunjukkan kehancuran hutan yang tidak terkendali. Hal ini dipicu oleh adanya pengelolaan hutan yang berparadigma timber extraction (penambangan kayu). Meskipun paradigma ini kemudian berubah menjadi timber management (manajemen kebun kayu) yang sedikit lebih maju dalam tataran konsep, namun prakteknya tidak jauh beda dengan era penambangan kayu yang masih berlanjut sampai sekarang ini (Mando et al., 2018).

Ketidakmampuan pemerintah mengatasi krisis kependudukan, lingkungan, dan ekonomi secara cepat telah menyadarkan berbagai pihak untuk menegakkan kembali apa yang disebut sebagai kekuatan lokal (empowering the local) (Mando et al., 2018). Sehubungan dengan itu, dewasa ini masyarakat mulai melakukan pengembangan hutan rakyat pada berbagai wilayah di Indonesia. Dako (2012) menyatakan bahwa pengelolaan hutan rakyat mesti dilaksanakan secara terencana, terarah, berkesinambungan agar dapat tercapai hasil yang optimal dan menguntungkan baik dari aspek ekologi, aspek sosial maupun dari aspek ekonomi. Secara ekologi bentuk hutan seperti ini mempunyai daya tahan terhadap serangan hama penyakit dan angin, mencegah pemanasan global dengan menyerap karbon, pengatur tata air, menjaga kesuburan tanah dan penyuplai oksigen, secara sosial dapat menjadi pengikat kebersamaan, sedangkan secara ekonomi, hutan rakyat memberikan keuntungan bagi masyarakat melalui pemanenan bertahap yang berkesinambungan.

Menurut Donie et. al (2001) kondisi tegakan merupakan hal penting yang perlu diketahui untuk menilai keberhasilan pengelolaan hutan rakyat. Kondisi tersebut dicerminkan oleh beberapa parameter diantaranya jumlah batang perhektar, sebaran diameter, dan tinggi tanaman. Lembaga Penelitian IPB (1990), menyatakan bahwa ada beberapa metode pengaturan hasil dalam pengelolaan hutan yang lestari yaitu berdasarkan luas, volume dan jumlah batang.

Oleh karena itu, kebutuhan informasi/data kondisi iklim sebagai salah satu sumber daya lahan untuk perencanaan, penyusunan dan pelaksanaan tata ruang khususnya dalam pengelolaan hutan rakyat adalah sangat penting. Kenyataan dari berbagai wilayah, menunjukkan bahwa kondisi iklim merupakan salah satu faktor yang banyak menimbulkan masalah fisik pada 
lahan yang pada akhirnya berakibat buruk kepada kehidupan sosial dan ekonomi masyarakat khususnya terjadinya kerusakan hutan setiap tahunnya yang berbeda-beda setiap wilayah, seperti wilayah Sumatera 0.09 jt.ha.th $^{-1}$, Jawa 0.02 jt.ha.th ${ }^{-1}$, Bali-Nusa Tenggara 0.14 jt.ha.th ${ }^{-1}$, Kalimantan 0.14 jt.ha.th ${ }^{-1}$, Sulawesi 0.07 jt.ha.th ${ }^{-1}$, Maluku-Papua 0. jt.ha.th ${ }^{-1}$ (KLHK, 2019).

Menurut Simon (2004), jenis tanaman untuk hutan rakyat harus memiliki beberapa kriteria yaitu: 1) sesuai dengan keadaan iklim, jenis tanah dan kesuburan tanah serta sifat fisik wilayah (environmentally friendly), 2) cepat menghasilkan dan dapat dibudidayakan oleh masyarakat dengan mudah (socially acceptable), 3) menghasilkan komoditas yang mudah dipasarkan dan memenuhi bahan baku industry (economically profitable). Hal tersebut menunjukkan bahwa peran data sumberdaya lahan khususnya kondisi iklim menjadi penting dan harus diperhatikan dalam penggunaan dan pemakaian lahan. Kesesuaian iklim yang dibahas dalam tulisan ini adalah tanaman sengon (Falcataria moluccana (Miq.)) yang diharapkan potensial untuk dikembangkan di desa Jati Bali Kabupaten Konawe Selatan.

Sengon ( $F$. moluccana (Miq.)) merupakan salah satu tanaman kehutanan tahunan yang relatif lebih pendek masa panennya dibandingkan tanaman kehutanan lainnya. Budidaya dan pemeliharaannya yang cukup mudah membuat tanaman sengon dijadikan alternatif oleh petani untuk meningkatkan pendapatannya (Putra et al., 2015). Kayu sengon cocok digunakan sebagai bahan baku industri seperti veneer, kayu lapis dan pulp. Berdasarkan hasil pengumpulan Data Kehutanan Triwulan Tahun 2017, jumlah produksi kayu bulat di Indonesia adalah 49.13 juta $\mathrm{m}^{3}$, dimana produksi kayu sengon sendiri sebesar 3.83 juta $\mathrm{m}^{3}(7.80 \%)$ dari total produksi kayu bulat Indonesia (Badan Pusat Statistik, 2017).

Tanaman sengon telah banyak ditanam dan dibudidayakan oleh masyarakat di Indonesia, salah satunya adalah anggota Kelompok Tani Hutan Bumi Hijau di Desa Jati Bali, Kecamatan Ranomeeto Barat, Kabupaten Konawe Selatan. Bibit tanaman sengon diperoleh dari bantuan pemerintah melalui program Kebun Bibit Rakyat (KBR). Menurut Nurlia dan Efendi (2012), Program KBR tersebut dapat secara khusus ditunjukan untuk menghijaukan lahan hutan rakyat dimana penanaman bibit hasil KBR digunakan untuk merehabilitasi lahan kritis, lahan kosong, dan lahan tidak produktif sebagai upaya percepatan rehabilitasi hutan dan lahan yang terdegradasi. Namun, hingga saat ini belum diketahui keadaan iklim di desa tersebut yang mempunyai hubungan erat dengan potensi pertumbuhani dan produktivitas tanaman sengon. Berdasarkan uraian tersebut, telah dilaksanakan penelitian yang bertujuan untuk mengetahui kondisi iklim dan potensi tegakan sengon di Desa Jati Bali Kabupaten Konawe Selatan.

\section{METODE}

\section{Lokasi dan Waktu Penelitian}

Penelitian ini dilaksanakan di Desa Jati Bali, Kecamatan Ranomeeto Barat, Kabupaten Konawe Selatan pada hutan rakyat dengan jenis tanaman sengon ( $F$. moluccana (Miq)), pada bulan Agustus hingga bulan November 2018. Lokasi penelitian secara geografis beada pada titik koordinat $04^{\circ} 05^{\prime} 12^{\prime \prime}-04^{\circ} 03^{\prime} 15^{\prime \prime}$ LS dan $122^{\circ} 23^{\prime} 15^{\prime \prime}-122^{\circ} 23^{\prime} 00^{\prime \prime} \mathrm{BT}$, pada ketinggian $108 \mathrm{~m} \mathrm{dpl}$.

\section{Bahan dan Alat}

Bahan yang digunakan dalam penelitian ini adalah tally sheet pengukuran, patok, tali rapia, peta lokasi penelitian, sedangkan alat yang digunakan adalah kamera digital, Global positioning system (GPS), aplikasi smart measure, meteran rol, pita meter, parang, spidol, dan alat hitung serta alat tulis menulis.

\section{Prosedur Kerja}

Prosedur kerja diawali dengan mengetahui luas populasi tegakan sengon, dimana luas tegakan sengon adalah 5.8 ha. Selanjutnya, untuk menentukan luas sampel, ditentukan terlebih dahulu intensitas samplingnya menggunakan pendekatan Boon dan Tideman (1950 dalam Soerianegara dan Indrawan, 1978), yakni untuk areal hutan yang luasnya $\geq 1.000$ ha intensitas sampling yang digunakan sebaiknya $2 \%$, kalau $<1.000$ ha Intensitas samplingnya sebaiknya 
$5 \%-10 \%$. Oleh karena itu, dalam penelitian ini dengan areal 5.8 ha maka intensitas sampling yang digunakan $6.2 \%$. Sehingga luas sampel adalah 0.3596 ha (5.8 ha x 6.2\%). Luas 1 petak ukur yang digunakan adalah $20 \mathrm{~m} \times 20 \mathrm{~m}$, maka jumlah petak ukur ada 9 (sembilan), yakni 0.3596 ha $=0.3596 \times 100000 \mathrm{~m}^{2}: 400 \mathrm{~m}^{2}=8.99$ (9 petak), dimana penempatan petak ukur dilakukan secara sistematik sampling, seperti contoh 3 petak ukur yang disajikan pada Gambar 1 , selanjutnya diukur parameter pohon yang ada di dalamnya yang meliputi diamater setinggi dada dan tinggi pohon.

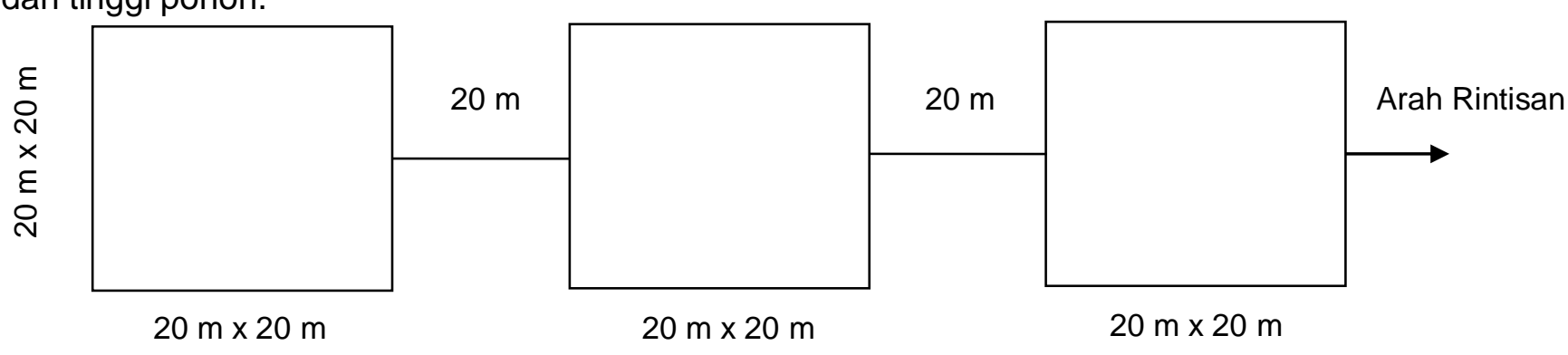

Gambar 1. Penempatan petak ukur secara sistematik Figure 1. Placement of plots systematically

\section{Variabel Pengamatan}

Variabel yang diamati dalam penelitian ini secara umum ada dua yakni kondisi iklim dan potensi tegakan sengon di Desa Jati Bali Kabupaten Konawe Selatan, sebagai berikut :

a. Kondisi iklim, meliputi : curah hujan rata-rata tahunan, curah hujan rata-rata bulanan, jumlah bulan basah, jumlah bulan kering, dan tipe iklim Schmidth Fergusson, serta suhu udara rata-rata tahunan dan rata-rata bulanan;

b. Potensi tegakan sengon, meliputi jumlah pohon per hektar (luas areal hutan rakyat dan jarak tanam), luas bidang dasar (diameter pohon setinggi dada), dan volume tegakan (tinggi total pohon).

Bersamaan dengan pengukuran parameter pohon pada setiap plot, dilakukan juga pengukuran ketinggian tempat menggunakan GPS, sementara penentuan jenis tanah menggunakan data sekunder.

\section{Analisis Data}

\section{a. Kondisi Iklim}

Data iklim dianalisis menggunakan metode tabulasi dan rata-rata, berdasarkan hasil pengukuran dari stasiun terdekat yakni Stasiun iklim milik BMKG Ranomeeto Kabupaten Konawe Selatan periode 10 tahun (2008 - 2017), meliputi curah hujan, hari hujan, dan suhu udara, sedangkan penentuan tipe iklim menggunakan metode Schmidth-Fergusson (1951 dalam Lakitan, 2002), dimana iklim dibagi menjadi 8 tipe berdasarkan pada perbandingan banyaknya bulan kering (BK) dan bulan basah (BB) yang dinyatakan dalam nilai Q (Quotient). BK adalah bulan dengan curah hujan $<60 \mathrm{~mm}$, BB adalah bulan dengan curah hujan $>100 \mathrm{~mm}$, bulan yang memiliki curah hujan $\geq 60-100 \mathrm{~mm}$, disebut bulan lembab (BL). Penentuan tipe iklim schmidth-Fergusson berdasarkan kriteria nilai $Q$ (Quotient) disajikan pada Tabel 1. 
Tabel 1. Klasifikasi Iklim Schmidth-Fergusson

Table 1. Climate distribution according to Schmidth-Fergusson

\begin{tabular}{llc}
\hline \multicolumn{1}{c}{ Tipe iklim $(1)$} & \multicolumn{1}{c}{ Vegetasi } & \multicolumn{1}{c}{ Kriteria } \\
\hline \multicolumn{1}{c}{$(2)$} & \multicolumn{1}{c}{$(3)$} \\
\hline \hline A. Sangat basah & Hutan hujan tropika & $0,000<\mathrm{Q}<0,143$ \\
B. Basah & Hutan hujan tropika & $0,143<\mathrm{Q}<0,333$ \\
C. Agak basah & Hutan rimba & $0,333<\mathrm{Q}<0,600$ \\
D. Sedang & Hutan musim & $0,600<\mathrm{Q}<1,000$ \\
E. Agak kering & Hutan sabana & $1,000<\mathrm{Q}<1,670$ \\
F. Kering & Hutan sabana & $1,670<\mathrm{Q}<3,000$ \\
G. Sangat kering & Padang ilalang & $3,000<\mathrm{Q}<7,000$ \\
H. Kering luar biasa & Padang ilalang & $7,000<\mathrm{Q}$
\end{tabular}

Sumber : Schmidth-Fergusson (1951 dalam Lakitan, 2002)

\section{b. Potensi Tegakan Sengon}

Parameter yang menunjukkan potensi tegakan sengon pada hutan rakyat adalah jumlah pohon, luas bidang dasar (LBDS), dan volume kayu pohon perhektarnya. Untuk itu dilakukan klasifikasi jenis-jenis pohon berdasarkan tingkat pertumbuhan selama hidupnya. Setelah itu ditentukan potensinya menurut jumlah pohon $(\mathrm{N})$, luas bidang dasar, dan volume kayu pohon.

\section{1) Jumlah pohon (N)}

Jumlah pohon pada setiap Petak Ukur (PU) ditentukan berdasarkan klasifikasi tingkat pertumbuhannya. Setiap pohon terlebih dahulu dimasukkan satu per satu sesuai dengan kriteria tersebut, sehingga didapatkan sejumlah pohon per PU (Mando et al., 2017). Selanjutnya, untuk memperoleh kerapatan dalam satu hektar, rata-rata jumlah pohon per PU di bagi dengan luas 1 Petak Ukur (0,04 ha).

\section{2) Luas bidang dasar $\left(\mathrm{m}^{2}\right)$}

Luas bidang dasar tidak saja menunjukkan jarak antar pohon dalam satuan luas, tetapi lebih daripada itu untuk menggambarkan penguasaan ruang tumbuh bagi setiap pohon. Berdasarkan pembagian di atas, maka selanjutnya dihitung LBDS dengan menggunakan rumus sebagai berikut (Simon, 2015) :

$$
\text { LBDS }=\frac{1}{4} \pi d^{2}
$$

dengan :

$$
\begin{array}{ll}
\mathrm{d} & =\text { diameter setinggi dada }(1,3 \mathrm{~m}) \\
\pi & =\text { konstanta dengan nilai } 3,1428
\end{array}
$$

Adanya parameter LBDS itu sendiri merupakan gambaran keadaan kerapatan tegakan dalam suatu lahan hutan rakyat. Kerapatan tegakan pohon tersebut telah dibuat klasifikasi khusus sebagai barometer dalam sebuah tabel sebagai berikut (Djuwadi, 2002 dalam Mando, 2006) :

Tabel 2. Kerapatan Tegakan Hutan Rakyat

Table 2. Standing Density of community forest

\begin{tabular}{cccc}
\hline $\begin{array}{c}\text { Lbds Pohon di HR } \\
\text { Per ha }\left(\mathrm{m}^{2}\right)\end{array}$ & Kualifikasi & $\begin{array}{c}\text { Ruang tumbuh pohon } \\
\text { Hutan Rakyat (\%) }\end{array}$ & $\begin{array}{c}\text { Ruang tumbuh } \\
\text { tanam pertanian di } \\
\text { bawah pohon (\%) }\end{array}$ \\
\hline \hline$(1)$ & $(2)$ & $(3)$ & $(4)$ \\
\hline $0-4$ & Tegal & $0-25$ & $75-100$ \\
$4-8$ & Jarang & $25-50$ & $50-75$ \\
$8-12$ & Sedang & $50-75$ & $25-75$ \\
$12-16$ & Rapat & $75-100$ & $0-25$
\end{tabular}




$$
>16 \quad \text { Sangat rapat }
$$

Sumber : Djuwadi (2002) dalam Mando (2006)

\section{3) Volume Kayu Pohon $\left(\mathrm{m}^{3}\right)$}

Setelah diperoleh luas bidang dasarnya, maka selanjutnya ditentukan volumenya. Volume kayu pohon dihitung berdasarkan rumus berikut (Djuwadi, 2002 dalam Mando, 2006) :

dengan :

$$
V=\text { LBDS. } T . f .
$$

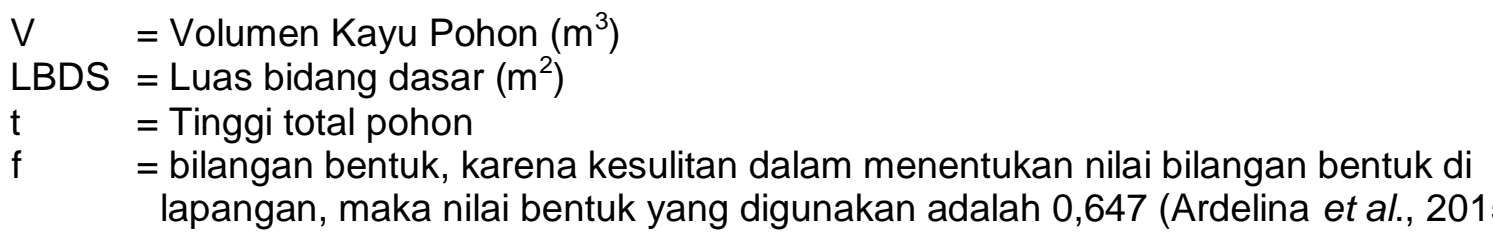

\section{HASIL DAN PEMBAHASAN}

\section{Kondisi Iklim}

Secara umum, kondisi iklim di Desa Jati Bali Kabupaten Konawe Selatan memiliki dua musim yakni musim kemarau dan musim hujan, dimana berdasarkan hasil pengukuran yang didapatkan dari Stasiun Klimatologi BMKG Ranomeeto Kendari selama 10 tahun (Periode 2008 2017), wilayah tersebut memiliki rata-rata tahunan curah hujan, hari hujan dan suhu udara yaitu $2662.6 \mathrm{~mm}$ selama 213.3 hari, dengan suhu udara minimum $23^{\circ} \mathrm{C}$ dan maksimum $32^{\circ} \mathrm{C}$, berada pada ketinggian tempat $108 \mathrm{~m}$ dpl. Pergantian musim kemarau dan musim hujan dipengaruhi oleh arah angin yaitu angin Barat daya pada bulan Juni sampai dengan bulan Januari dan angin Timur/Tenggara pada bulan Februari sampai bulan Agustus. Rata-rata bulanan curah hujan, hari hujan dan suhu udara di desa Jati Bali Kabupaten Konawe Selatan disajikan pada Gambar 2.

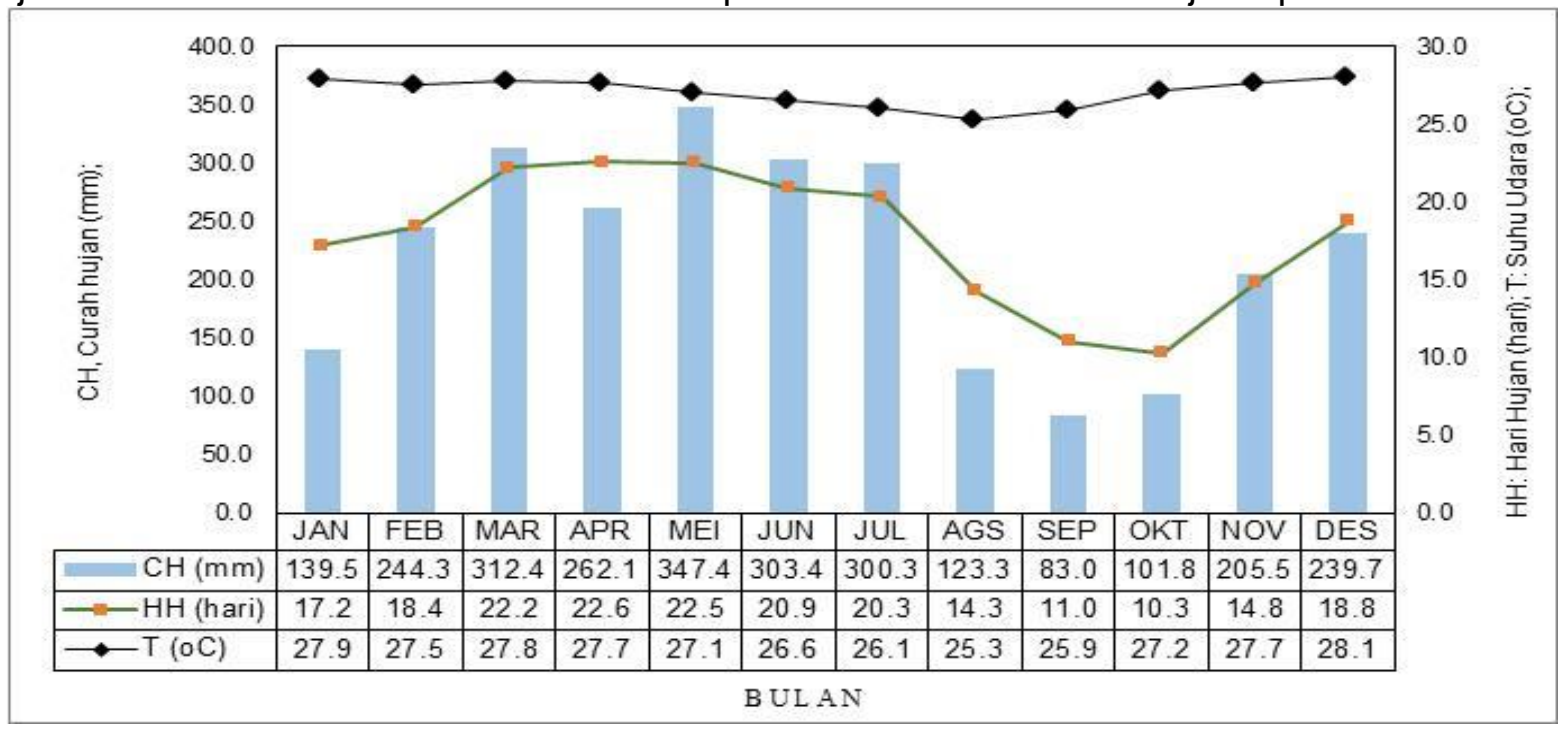

Gambar 2. Fluktuasi rata-rata bulanan curah hujan, hari hujan dan suhu udara di Desa Jati Bali Kabupaten Konawe Selatan Periode 2008-2017

Figure 2. Fluctuations in the average monthly rainfall, rainy days and air temperatures in the village of Jati Bali South Konawe Regency 2008-2017 Period 
Gambar 2 menunjukkan bahwa curah hujan dan hari hujan rata-rata bulanan di di desa Jati Bali Kabupaten Konawe Selatan cukup berfluktuasi sedangkan suhu udara relatif sama dengan kisaran terendah $25.3^{\circ} \mathrm{C}$ (Agustus) dan tertinggi $28.1^{\circ} \mathrm{C}$ (Desember). Rata-rata bulanan curah hujan tertinggi terjadi pada bulan Mei yakni $347.4 \mathrm{~mm}$ dengan rata-rata hari hujan 22.5 hari, sedangkan terendah terjadi pada bulan September yakni $83.0 \mathrm{~mm}$ dengan hari hujan rata-rata sebesar 11 hari, sementara hari hujan paling lama terjadi di bulan April selama 22.6 hari dengan curah hujan mencapai $262.1 \mathrm{~mm}$, sedangkan tercepat terjadi pada bulan Oktober yakni 10.3 hari dengan curah hujan mencapai $101.7 \mathrm{~mm}$. Berdasarkan kriteria rata-rata curah hujan bulanan tersebut, menurut metode Schmidth - Fergusson di Desa Jati Bali terdapat rata-rata jumlah bulan basah (BB) 9.2 dan rata-rata bulan kering (BK) 1.5, sehingga memiliki nilai $Q$ sebesar 0.16, artinya bahwa lokasi penelitian bertipe iklim $B$ atau tergolong Basah dengan vegetasi hutan hujan tropika. Kenyataan tersebut mengindikasikan bahwa lokasi penelitian sesuai untuk pengembangan tanaman Sengon. Menurut Griffoen 1954 dalam Setyawan (2002), di daerah tropis seperti Indonesia, sengon dapat tumbuh dengan baik pada tanah-tanah yang lembab dengan tipe iklim $A$, B dan C menurut klasifikasi Schmidt dan Ferguson.

Menurut Ardiansyah (2017), syarat tumbuh yang ideal bagi tanaman sengon adalah wilayah dengan curah hujan tahunan berkisar antara $2000 \mathrm{~mm}-2700 \mathrm{~mm}$, bahkan dapat mencapai $4000 \mathrm{~mm}$ dengan musim kering lebih dari 4 bulan. Lebih lanjut dijelaskan bahwa pohon sengon memiliki tingkat evapotranspirasi yang sangat tinggi, sehingga untuk dapat tumbuh secara optimal membutuhkan iklim yang basah dengan curah hujan tahunan $2000-3500 \mathrm{~mm}$ dengan suhu udara berkisar $22^{\circ} \mathrm{C}-33^{\circ} \mathrm{C}$. Oleh karena itu, dapat dikemukakan bahwa desa Jati Bali Kabupaten Konawe Selatan sesuai untuk pengelolaan hutan rakyat dengan mengembangkan tanaman Sengon, karena di lokasi penelitian tersebut memiliki rata-rata tahunan curah hujan $2662.6 \mathrm{~mm}$ dengan suhu udara berkisar $23^{\circ} \mathrm{C}-32^{\circ} \mathrm{C}$ dengan rata-rata bulanan $25.3^{\circ} \mathrm{C}-28.1^{\circ} \mathrm{C}$.

\section{Potensi Tegakan Sengon}

Pengelolaan hutan selalu ditujukan untuk mendapatkan manfaat optimum. Memahami manfaat hutan, mengandung arti harus dilakukannya penilaian terhadap semua jenis manfaat yang dapat dihasilkan oleh hutan tersebut, baik yang bersifat manfaat nyata (tangible) maupun tidak nyata (intangible) (Onrizal dan Sulistiyono, 2002). Penilaian terhadap manfaat yang bersifat nyata dapat berupa penilaian volume pohon atau luas bidang dasar, untuk memprediksi volume kayu yang dihasilkan pada beberapa tahun ke depannya. Penilaian terhadap manfaat tidak nyata dapat berupa penilaian terhadap jasa lingkungan, misalnya hutan sebagai penyedia oksigen bagi udara di sekitarnya atau menciptakan iklim mikro yang berbeda dengan di luarnya.

Kebun Bibit Rakyat (KBR) yang berada di Desa Jati Bali Kabupaten Konawe Selatan didirikan sejak tahun 2014 yang dibentuk oleh Kelompok Tani Bumi Hijau serta didukung oleh BPDAS-HL Sampara sebagai salah satu bentuk program pemanfaatan hutan rakyat. Jenis tanaman yang diusahakan dalam pemanfaatan Kebun Bibit Rakyat tersebut adalah tanaman sengon ( $F$. moluccana (Miq.)). Tanaman sengon dianggap memiliki nilai ekonomi yang cukup tinggi serta dapat dimanfaatkan sebagai bahan bangunan serta kebutuhan lainnya dan masa tebang kayu sengon yang tidak terlalu lama merupakan salah satu alasan petani tertarik membudidayakan kayu sengon di lahan yang dimiliki.

Potensi hutan merupakan nilai kekayaan yang terkandung dalam suatu lahan hutan baik secara nyata ada pada saat pengamatan maupun perkiraan perkembangan atau pertumbuhan. Pada hutan rakyat tanaman sengon yang ada di wilayah penelitian memiliki umur yang sama yakni 4 tahun. Jumlah pohon di lokasi penelitian pada 9 petak ukur yang diamati disajikan pada Tabel 3. 
Tabel 3. Jumlah Pohon Sengon Per hektar pada Hutan Rakyat di Desa Jati Bali Kabupaten Konawe Selatan Tahun 2018

Table 3. Number of Sengon Per hectare in Community Forests in Jati Bali Village, South Konawe Regency in 2018

\begin{tabular}{ccc}
\hline No. PU & $\begin{array}{c}\text { Jumlah Pohon Per Pu } \\
\left(\text { Btg.Pu }^{-1}\right)\end{array}$ & $\begin{array}{c}\text { Jumlah Pohon Per ha } \\
\left(\text { Btg.ha }^{-1}\right)\end{array}$ \\
\hline$(1)$ & $(2)$ & $(3)$ \\
\hline 1 & 58 & 1.450 \\
2 & 42 & 1.050 \\
3 & 42 & 1.050 \\
4 & 23 & 575 \\
5 & 31 & 775 \\
6 & 31 & 775 \\
7 & 32 & 800 \\
8 & 22 & 550 \\
9 & 38 & 950 \\
\hline \hline
\end{tabular}

Sumber : Data Primer diolah Tahun 2018 (Palebangan, 2019)

Tabel 3 menunjukkan bahwa jumlah tanaman sengon pada hutan rakyat di Desa Jati Bali yaitu sebanyak 886 btg.ha- ${ }^{-1}$. dengan luas lahan 5.8 ha dengan jarak tanam $2 \mathrm{~m} \times 5 \mathrm{~m}$. Jarak tanam merupakan salah satu faktor yang dapat menentukan produktivitas tanaman karena berpengaruh terhadap besar kecilnya intensitas cahaya yang dibutuhkan bagi tanaman. Rata-rata diameter tanaman pohon per petak ukur mencapai $10.73 \mathrm{~cm}$, dengan tinggi bebas cabang $7.32 \mathrm{~m}$ dan tinggi total mencapai $12.38 \mathrm{~m}$. Hasil perhitungan Luas bidang dasar areal sengon di wilayah penelitian berdasarkan parameter yang diamati disajikan pada Tabel 4.

Tabel 4. Luas Bidang Dasar di Desa Jati Bali Kabupaten Konawe Selatan Tahun 2018

Table 4. Area of Basic Fields located in Jati Bali Village, South Konawe in 2018

\begin{tabular}{ccc}
\hline Petak Ukur & $\begin{array}{c}\text { LBDS Pohon per Pu } \\
\left(\mathrm{m}^{2} . \mathrm{Pu}^{-1}\right)\end{array}$ & $\begin{array}{c}\text { LBDS Pohon per ha } \\
\left(\mathrm{m}^{2} . \mathrm{ha}^{-1}\right)\end{array}$ \\
\hline$(1)$ & $(2)$ & $(3)$ \\
\hline 1 & 0.86 & 21.61 \\
2 & 0.64 & 15.94 \\
3 & 0.51 & 15.61 \\
4 & 0.12 & 3.03 \\
5 & 0.13 & 3.31 \\
6 & 0.19 & 4.73 \\
7 & 0.35 & 8.83 \\
8 & 0.30 & 7.53 \\
9 & 0.29 & 7.28 \\
\hline \multicolumn{3}{c}{} \\
\hline
\end{tabular}

Sumber: Data Primer Diolah Tahun 2018 (Palebangan, 2019)

Tabel 4 menunjukkan bahwa luas bidang dasar tanaman sengon per hektar di Desa Jati Bali yakni $9.76 \mathrm{~m}^{2}$, artinya bahwa dengan nilai luas bidang dasar tersebut, berdasarkan klasifikasi kerapatan tegakan pohon (Djuwadi, 2002 dalam Mando, 2006), kerapatan tanaman sengon di Desa Jati Bali tergolong sedang, yakni 50-75\% dari ruang tumbuh pohon hutan rakyat dan $25-50 \%$ dapat menjadi ruang tumbuh tanaman pertanian di bawah pohon (Tabel 5). Kenyataan tersebut mengindikasikan bahwa pada hutan rakyat di Desa Jati Bali Kabupaten Konawe selatan masih terdapat ruang kosong untuk tumbuhnya jenis vegetasi lainnya, namun demikian, bila dikelola dengan baik menggunakan teknologi yang tepat, pertumbuhan sengon dapat lebih cepat, karena ruang pertumbuhan diameter dan tajuk sengon masih terbuka. 
Tabel 5. Volume Tegakan Sengon perhektar pada Hutan Rakyat di Desa Jati Bali Kabupaten Konawe Selatan Tahun 2018

Table 5. Sengon Upright Volume per hectare in Community Forest in Jati Bali Village, South Konawe Regency in 2018

\begin{tabular}{cccc}
\hline \hline No & Petak & $\begin{array}{c}\text { Volume Pohon per Petak Ukur } \\
\left(\mathrm{m}^{3} \cdot \mathrm{Pu}^{-1}\right)\end{array}$ & $\begin{array}{c}\text { Volume Pohon per Hektar } \\
\left(\mathrm{m}^{3} . \mathrm{Ha}^{-1}\right)\end{array}$ \\
\hline$(1)$ & $(2)$ & $(3)$ & $(4)$ \\
\hline 1 & 1 & 10.31 & 257.75 \\
2 & 2 & 5.95 & 148.75 \\
3 & 3 & 5.70 & 142.50 \\
4 & 4 & 0.62 & 15.50 \\
5 & 5 & 0.89 & 22.25 \\
6 & 6 & 0.77 & 19.25 \\
7 & 7 & 4.75 & 118.75 \\
8 & 8 & 1.92 & 48.00 \\
9 & 9 & 2.98 & 74.50 \\
\hline Jumlah perhektar (ha) & & 94.15 \\
\hline
\end{tabular}

Sumber: Data Primer Diolah Tahun 2018 (Palebangan, 2019)

Tabel 5. menunjukkan bahwa rata-rata volume tegakan sengon pada hutan rakyat di Desa Jati Bali Kabupaten Konawe Selatan yakni $94.15 \mathrm{~m}^{3} \mathrm{ha}{ }^{-1}$. Nilai tersebut mengindikasikan bahwa pertumbuhan riap volume cukup baik, meskipun tidak berada di atas normal karena berdasarkan perhitungan didapatkan volume tegakan minimum $39.5 \mathrm{~m}^{3} \mathrm{ha}^{-1}$ dan maksimum $149 \mathrm{~m}^{3} \mathrm{ha}^{-1}$. Namun apabila dilakukan pemeliharaan, maka dalam kurun waktu 2 (dua) tahun pertumbuhannya akan lebih baik. Hal ini menunjukkan bahwa potensi kayu sengon di desa Jati Bali Kabupaten Konawe Selatan cukup besar sehingga keberadaannya harus terus dikembangkan. Hardjanto (2003) menyatakan bahwa potensi kayu sengon yang berasal dari hutan rakyat cukup besar, hanya karena belum adanya pola pemantauan yang baik sehingga perannya belum terlihat dalam statistik yang terpublikasikan.

Menurut Puspitojati et al (2014) Potensi tegakan kayu yang dihasilkan pada setiap pola pengembangan sangat dipengaruhi oleh jumlah pohon persatuan luas, diameter, dan tinggi tanaman, sedangkan diameter dan tinggi tanaman dipengaruhi oleh faktor eksternal dari petani seperti kesuburan tanah, dan iklim, sementara pola pengembangannya ditentukan oleh faktor internal seperti pengetahuan petani tentang jarak tanam, sistem silvikultur, dan sebagainya. Kenyataan tersebut mengindikasikan bahwa produktivitas suatu pohon ditentukan oleh dua faktor yakni faktor keturunan (genetik) dan faktor lingkungan.

Yuliani dan Diniyati (2004), menyatakan bahwa produktivitas tanaman yang optimal, hanya bisa terwujud bila faktor genetik dan faktor lingkungan sama-sama diperhatikan, karena suatu pohon dengan tinggi dan diameter yang baik tapi bentuk batangnya bengkok akan mempunyai nilai jual yang rendah. Menurut Lavalle et al., (2009) dan Kandari et al (2015), faktor lingkungan yakni tanah dan iklim khususnya curah hujan saling menunjang dalam proses pertumbuhan tanaman sehingga untuk mencapai pertumbuhan dan produktivitas yang optimum harus memenuhi persyaratan tanah dan iklim terutama curah hujan sebagai sumber air. Dengan demikian, dapat dikemukakan bahwa potensi kayu sengon yang cukup tinggi pada hutan rakyat di Desa Jati Bali Kabupaten Konawe Selatan antara lain karena didukung oleh kondisi iklim di wilayah tersebut yang tergolong sesuai dengan syarat pertumbuhan sengon.

\section{KESIMPULAN DAN SARAN}

\section{Kesimpulan}

Berdasarkan hasil peneltian yang dilakukan, maka dapat disimpulkan sebegai berikut :

a. Kondisi iklim di desa Jati Bali Kabupaten Konawe Selatan, secara umum tergolong tipe iklim B atau basah (metode Schmidth-Fergusson), termasuk kategori hutan hujan tropika 
dengan jumlah rata-rata bulan basah (BB) 9.2 dan bulan kering (BK) 1.5 dengan nilai $Q$ sebesar 0.16. Curah hujan rata-rata tahunan yakni $2662.6 \mathrm{~mm}$, dimana curah hujan ratarata bulanan tertinggi terjadi pada bulan Mei sebesar $347.4 \mathrm{~mm}$ dengan jumlah hari hujan rata-rata sebesar 22.5 hari dan terendah pada bulan September sebesar $83.0 \mathrm{~mm}$ dengan hari hujan rata-rata sebesar 11 hari, sementara hari hujan terlama terjadi pada bulan April selama 22.6 hari dengan curah hujan mencapai $262.1 \mathrm{~mm}$ dan tercepat terjadi di bulan Oktober selama 10.3 hari dengan curah hujan mencapai $101.8 \mathrm{~mm}$. Suhu udara rata-rata tahunan berkisar $23^{\circ} \mathrm{C}$ (minimum) $-32^{\circ} \mathrm{C}$ (maksimum), dengan rata-rata bulanan terendah $25.3^{\circ} \mathrm{C}$ (Agustus) dan tertinggi $28.1^{\circ} \mathrm{C}$ (Desember). Hal tersebut mengindikasikan bahwa secara klimatologis di desa Jati Bali Kabupaten Konawe Selatan sesuai untuk pengelolaan hutan rakyat dengan mengembangkan tanaman Sengon ( $F$. moluccana (Miq.)).

b. Potensi tegakan sengon di desa Jati Bali Kabupaten Konawe Selatan cukup tinggi dengan rata-rata jumlah pohon adalah 866 btg.ha-1, luas bidang dasar sebesar $9.76 \mathrm{~m}^{2}$.ha-1, dan rata-rata volume tegakan sebesar $94.15 \mathrm{~m}^{3} \mathrm{ha}^{-1}$.

\section{Saran}

Berdasarkan hasil penelitian, direkomendasikan beberapa saran sebagai berikut :

a. Peran pemerintah perlu diintensifkan, baik melalui sosialisasi dan pelatihan, juga yang penting adalah bantuan bibit dan sarana prasarana lainnya untuk mendukung pengembangan tanaman sengon di desa Jati Bali Kabupaten Konawe Selatan.

b. Peran masyarakat khususnya dapat mencadangkan lahannya yang lebih luas lagi untuk pengembangan tanaman sengon agar tidak saja memberikan manfaat dari aspek ekonomi, akan tetapi dari aspek lingkungan juga begitu besar.

c. Peran para peneliti selanjutnya dapat melanjutkan pendalaman berupa evaluasi dan kajian tentang peningkatan kesejahteraan masyarakat di lokasi penelitian melalui pengelolaan hutan rakyat dengan pengembangan tanaman sengon.

\section{UCAPAN TERIMA KASIH}

Ucapan terima kasih penulis sampaikan kepada saudari Suhartin Triyani Palebangan yang telah membantu dalam pengumpulan data di lapangan. Kami sampaikan pula terima kasih kepada para petani hutan rakyat atas diizinkannya dilaksanakan penelitian di lahan miliknya. Kepada Kepala BMKG Maritim Kendari penulis menyampaikan terima kasih atas ketersediaan data iklimnya. Terkhusus kepada Dekan Fakultas Kehutanan dan IImu Lingkungan Universitas Halu Oleo (FHIL UHO), kami ucapkan terima kasih karena telah memberikan izin guna terselengaranya penelitian ini dan memberikan bantuan dana guna penyusunan artikel sehingga dapat berjalan dengan lancar dan selanjutnya dapat dipresentasikan pada kegiatan Seminar Nasional yang diselenggarakan di Universitas Mataram kerjasama dengan Komunitas Manajemen Hutan Indonesia (KOMHINDO) pada tanggal 2 November 2019.

\section{DAFTAR PUSTAKA}

Ardelina, A., Tatang, T. dan Muhdin. (2015). Model Volume Pohon Sengon Untuk Menilai Kehilangan Keuntungan Petani Hutan Rakyat. Jurnal Penelitian Hutan Tanaman. 12 (2), 131-139.

Ardiansyah, T. (2017). Pohon Sengon (Paraserianthes falcataria): Budidaya, Jenis, dan Keuntungan. 18 Oktober 2019. Diunduh dari https://foresteract.com/pohon-sengonparaserianthes-falcataria/.

Badan Pusat Statistik. (2017). Statistik Produksi Kehutanan 2017. Diunduh dari https://bulelengkab.go.id/assets/instansikab/126/bankdata/statistik-produksikehutanan-indonesia-2017-55.pdf. 
Bansook R., N. Phirun and C. Chhun. (2011). Agricultural Development and Climate Change: The Case of Cambodia. CDRI Publication, Working Paper Series, No. 65. CDRI Cambodia's Leading Independent Development Policy Research Institute.

Baskorowati, L. (2014). Budidaya Sengon Unggul (Falcataria moluccana) untuk Pengembangan Hutan Rakyat. Bogor : IPB Press.

Dako, F.X. (2012). Rancangan Pembangunan Hutan Rakyat Di Indonesia. Jurnal Partner Vol 19 No. 1 Tahun 2012. Buletin Pertanian Terapan. Program Studi Manajemen Sumberdaya Hutan Politeknik Pertanian Negeri Kupang. Jl. Adi Sucipto Penfui, P. O. Box. 1152, Kupang 85011.

Donie, S., Mashudi dan E. Irawan. 2001. Kemitraan Dalam Rangka Pengembangan Hutan Rakyat. Kasus di Kabupaten Klaten, Karanganyar dan Blitar. Buletin Teknologi Pengelolaan DAS No. VII, 1, 2001 hlm 42-62. Badan Penelitian dan Pengembangan Kehutanan Balai Teknologi Pengelolaan DAS Surakarta.

Hardjanto. (2003). Keragaan dan Pengembangan Usaha Kayu Rakyat di Pulau Jawa. Disertasi Doktor. Program Pasca Sarjana., IPB. Bogor. Tidak diterbitkan.

Kandari, A.M., Z. Uslinawaty, dan M. Ilton. (2020). Vegetation Types, Climatic Conditions and Trigona sp. Honey Quality in Onewila Village, Ranomeeto District South Konawe Regency. Jurnal Lahan Suboptimal: Journal of Suboptimal Lands ISSN: 2252-6188 (Print), ISSN: 2302-3015 (Online, www.jlsuboptimal.unsri.ac.id) Vol. 9, No.1:57-63 April 2020 DOI: https://doi.org/10.33230/JLSO.9.1.2020.468.

Kandari, A.M., S. Alam, Halim. (2019a). Conventional Land Management of Agro-Forestry in Different Slope Positions Based on Soil Chemical Properties in Districts of North Moramo, South Konawe Indonesia. Journal Bioscience Research Vol. 16(3): 25332543. Journal by Innovative Scientific Information \& Services Network

Kandari, A.M, S. Baja, A. Ala, Kaimuddin, S. Kasim, Y. Taufik. (2019b). Promoting Sustainable Agricultural Management Through Spatio Temporal Optimization of Food Crop Land Based on Pedo-Agroclimate at Kalalasi Region, Southeast Sulawesi, Indonesia. The 1st International Conference on Agriculture and Rural Development. IOP Conf. Series: Earth and Environmental Science 383 (2019) 012005. doi:10.1088/1755$1315 / 383 / 1 / 012005$

Kandari, A.M, S.Kasim, M.A.Limi, J. Karim. (2015). Land Suitability Evaluation for Plantation Forest Development Based on Multi-criteria Approach. Journal Agriculture, Forestry and Fisheries Vol. 4(5): 228-238. Science Publishing Group.

Kandari, A.M., Zulkarnain dan S. Jufri. (2014). Kesesuaian Agroklimat untuk Pengembangan Jambu Mete di Kabupaten Konawe Selatan Provinsi Sulawesi Tenggara. Jurnal Agriplus, 24(2), 123-135, Faperta Unhalu.

Kandari, A.M., L.O. Safuan, dan LM Amsil. (2013). Evaluasi Kesesuaian Lahan Untuk Pengembangan Tanaman Kopi Robusta (Coffea canephora) Berdasarkan Analisis Data Iklim Menggunakan Aplikasi Sistem Informasi Geografi. Jurnal Agroteknos Vol 3(1); 8-13. Jurusan Agroteknologi Faperta UHO.

Lakitan, B. 2002. Dasar-dasar Klimatologi. Jakarta: Raja Grafindo Persada.

[KLHK] Kementerian Lingkungan Hidup dan Kehutanan. (2019). Merawat Peradabandi Berbagai Tapak, Geliatnya Berangsur Tumbuh Pada Skala Ekonomi Yang Memeratakan Kesejahteraan Antar Wilayah. Laporan Kinerja KLHK, 2019. Jakarta. Indonesia.

Lavalle, C., Micale F., Houston T. D., Camia A., Hiederer R., Lazar C., Conte C., Amatulli G., Genovese G. (2009). Climate Change in Europe. Impact on Agriculture and Forestry. A. Review, Agron. Sustain. Dev. 29, 433-446. 
Lembaga Penelitian Institut Pertanian Bogor. (1990). Sistem Pengelolaan Hutan Rakyat. Bogor: Lembaga Penelitian Institut Pertanian Bogor.

Mando, L.O.A.S., U.O. Hasani, L.O. Midi, dan S. Bana. (2018). Potensi dan Pola Hutan Rakyat di Dusun Singlar Kabupaten Sleman. Seminar Nasional Silvikultur $V$ dan Kongres Masyarakat Silvikultur Indonesia IV : Silvikultur untuk Hutan Produksi Lestari dan Rakyat Sejahtera. Banjar Baru. 23 Agustus, 2018.

Mando, L.O.A.S., U.O. Hasani, L.O. Midi, dan S. Bana. (2017). Potensi dan Struktur Tegakan Jati di Resort Polisi Hutan (RPH) Madampi Kabupaten Muna Barat. Seminar Nasional Riset Kuantitatif Terapan. Kendari, 8 April 2017.

Mando, L.O.A.S. (2006). Penaksiran Potensi Kayu Dari Hutan Rakyat (Studi Kasus di Dusun Singlar, Glagaharjo, Kec. Cangkringan, Kab. Sleman). Skripsi. Yogyakarta : Jurusan Manajemen Hutan, Fakultas Kehutanan, Universitas Gadjah Mada.

Nurlia, A. dan Efendi A.W. (2012). Kebun Bibit Rakyat (KBR): Sarana Pengembangan Kayu Potensial Hutan Rakyat di Provinsi Bengkulu. Prosiding Seminar Hasil Penelitian Balai Penelitian Kehutanan (BPK) Palembang Peluang dan Tantangan Pengembangan Usaha Kayu Rakyat Palembang, 23 Oktober 2012.

Onrizal dan Sulistiyono, N. (2002). Metode Penilaian Tegakan Hutan Tanaman Industri. Medan : Fakultas Pertanian Program IImu Kehutanan Universitas Sumatera Utara.

Palebangan, S.T. (2019). Potensi Tegakan Sengon (Falcataria Moluccana) Pada Hutan Rakyat di Desa Jati Bali Kecamatan Ranomeeto Barat Kabupaten Konawe Selatan. Skripsi (S1). Jurusan Kehutanan. Fakultas Kehutanan dan IImu Lingkungan Universitas Halu Oleo.

Puspitojati, T., M.Y. Mile, E.Fauziah, dan D.Darusman. (2014). Hutan Rakyat. Sumbangsih Masyarakat Pedesaan untuk Hutan Tanaman. (Editor : Bahruin). Penerbit PT. Kanisius (Anggota IKAPI), Jl. Cempaka 9, Deresan, Caturtunggal, Depok, Sleman, Daerah Istimewa Yogyakarta 55281, Imdonesia.

Putra, D. S. A., Dyah, A. H. L. dan M, Affandi, I. (2015). Kelayakan Finansial dan Prospek Pengembangan Agribisnis Sengon (Albazia falcataria) Rakyat Di Kecamatan Kemiling Kota Bandar Lampung. Jurusan Agribisnis, Fakultas Pertanian, Universitas Lampung.

Setyawan H. (2002). Aspek Ekonomi Pengusahaan Hutan Rakyat Sengon di Kabupaten Sukabumi [Tesis]. Bogor: Fakultas Kehutanan. Institut Pertanian Bogor.

Simon, H. (2015). Metode Inventore Hutan. Yogyakarata : Pustaka Pelajar. Yogyakarta

Simon, H. (2004). Aspek Sosio-Teknis Pengelolaan Hutan Jati di Jawa. Pustaka Pelajar, Yogyakarta.

Soerianegara, I., dan A.Indrawan (1978). Ekologi Hutan Indonesia, Bogor : Laboratorium Ekologi Hutan Fakultas Kehutanan Institut Pertanian Bogor.

Yuliani, S.E., dan D. Diniyati. (2004). Identifikasi Masalah Pengembangan Hutan Rakyat di Desa Boja, Kecamatan Majenang, Kabupaten Cilacap. Al-Basia No. 1/thn 1/Januari/2004. HIm 31-38. Loka Litbang Hutan Monsoon Ciamis. 